Data Communications For Engineers 


\section{Macmillan New Electronics Series}

Series Editor: Paul A. Lynn

Rodney F. W. Coates, Underwater Acoustic Systems

W. Forsythe and R. M. Goodall, Digital Control

C. G. Guy, Data Communications for Engineers

Paul A. Lynn, Digital Signals, Processors and Noise

Paul A. Lynn, Radar Systems

A. F. Murray and H. M. Reekie, Integrated Circuit Design

F. J. Owens, Signal Processing of Speech

Dennis N. Pimm, Television and Teletext

M. J. N. Sibley, Optical Communications

Martin S. Smith, Introduction to Antennas

P. M. Taylor, Robotic Control

G. S. Virk, Digital Computer Control Systems

Allan Waters, Active Filter Design

\section{Series Standing Order}

If you would like to receive future titles in this series as they are published, you can make use of our standing order facility. To place a standing order please contact your bookseller or, in case of difficulty, write to us at the address below with your name and address and the name of the series. Please state with which title you wish to begin your standing order. (If you live outside the United Kingdom we may not have the rights for your area, in which case we will forward your order to the publisher concerned.)

Customer Services Department, Macmillan Distribution Ltd Houndmills, Basingstoke, Hampshire, RG21 2XS, England. 


\title{
Data Communications for Engineers
}

\author{
C. G. Guy \\ Department of Engineering \\ University of Reading
}

Macmillan New Electronics

Introductions to Advanced Topics

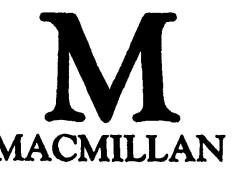


(C) C. G. Guy 1992

All rights reserved. No reproduction, copy or transmission of this publication may be made without written permission.

No paragraph of this publication may be reproduced, copied or transmitted save with written permission or in accordance with the provisions of the Copyright, Designs and Patents Act 1988, or under the terms of any licence permitting limited copying issued by the Copyright Licensing Agency, 90 Tottenham Court Road, London W1P 9HE

Any person who does any unauthorised act in relation to this publication may be liable to criminal prosecution and civil claims for damages.

First published 1992 by

MACMILLAN EDUCATION LTD

Houndmills, Basingstoke, Hampshire RG21 2XS

and London

Companies and representatives

throughout the world

ISBN 978-0-333-55501-9 ISBN 978-1-349-21915-5 (eBook)

DOI 10.1007/978-1-349-21915-5

A catalogue record for this book is available fro the British Library. 


\section{Contents}

Series Editor's Foreword viii

Preface $\quad$ ix

1 Introduction 1

1.1 Why do systems communicate? 1

1.2 How do systems communicate? 2

1.3 Information content of digital codes 4

1.4 Data communications $\quad 8$

1.5 Standards $\quad 11$

1.6 The standards organisations $\quad 12$

1.7 An example of a standard 14

$\begin{array}{ll}1.8 \text { Layered communications } & 14\end{array}$

$\begin{array}{ll}1.9 \text { Summary } & 18\end{array}$

2 Physical Communications Channels 20

2.1 Types of channel $\quad 22$

2.2 Direction of data flow 23

2.3 Characteristics of channels 24

2.4 Channel sharing or multiplexing $\quad 30$

2.5 Physical media $\quad 32$

2.6 Transmission modes $\quad 37$

2.7 Summary $\quad 39$

3 Baseband Digital Transmission 40

3.1 Pulse shaping $\quad 40$

3.2 Line codes 41

3.3 Detection of digital signals in noise 49

3.3 Summary $\quad 52$

4 Analog Data Transmission 53

4.1 Amplitude shift keying (ASK) 53

4.2 Frequency shift keying (FSK) 55 
4.3 Phase shift keying (PSK) 56

4.4 Detection of analog signals in noise $\quad 58$

$\begin{array}{ll}4.5 \text { Summary } & 60\end{array}$

5 Error Control and Data Compression Codes 61

5.1 Introduction 61

5.2 Block codes $\quad 63$

5.3 Cyclic codes $\quad 68$

5.4 Convolution codes $\quad 73$

5.5 Codes for data compression $\quad 76$

$\begin{array}{ll}5.6 \text { Summary } & 79\end{array}$

6 Physical Layer Standards $\quad 80$

6.1 Telephone channels $\quad 80$

6.2 Modem standards $\quad 83$

6.3 Standards related to the use of modems 85

6.4 Modem interface standards $\quad 86$

6.5 Common data communications protocols $\quad 90$

6.6 The Integrated Services Digital Network 90

6.7 Summary 93

7 The Data Link Layer $\quad 95$

7.1 Logical links 95

7.2 The functions of the data link layer 96

7.3 Link topology 97

7.4 Flow control $\quad 99$

7.5 Error control 101

7.6 Character-oriented protocols 102

$\begin{array}{ll}7.7 \text { Bit-oriented protocols } & 104\end{array}$

7.8 Implementation of the link layer 108

7.9 Commercial link layer protocols 109

$\begin{array}{ll}7.10 \text { Summary } & 110\end{array}$

8 The Higher Layers of the

Protocol Hierarchy

8.1 The network layer

8.2 The transport layer $\quad 119$

8.3 The session layer $\quad 122$

8.4 The presentation layer 123

8.5 The application layer 124

8.6 Summary 124 
9 Local Area Networks $\quad 126$

9.1 LAN topologies $\quad 126$

9.2 Media access methods $\quad 132$

9.3 Problems with LANS 135

9.4 Interconnecting local area networks 137

9.5 Fibre Distributed Data Interface 139

9.6 IEEE 802 standards $\quad 141$

9.7 Summary 143

10 The Future of Data Communications 144

10.1 Optical fibre networks $\quad 144$

10.2 Fast packet switching and frame relay 144

10.3 Making networking easier 145

$\begin{array}{ll}10.4 \text { Summary } & 147\end{array}$

$\begin{array}{ll}\text { Glossary of Terms and Acronyms } & 147\end{array}$

$\begin{array}{lr}\text { Bibliography } & 162\end{array}$

$\begin{array}{lr}\text { List of Standards } & 164\end{array}$

$\begin{array}{lr}\text { Index } & 169\end{array}$ 


\section{Series Editor's Foreword}

The rapid development of electronics and its engineering applications ensures that new topics are always competing for a place in university and polytechnic courses. But it is often difficult for lecturers to find suitable books for recommendation to students, particularly when a topic is covered by a short lecture module, or as an option.

Macmillan New Electronics offers introductions to advanced topics. The level is generally that of second and subsequent years of undergraduate courses in electronic and electrical engineering, computer science and physics. Some of the authors will paint with a broad brush; others will concentrate on a narrower topic, and cover it in greater detail. But in all cases the titles in the Series will provide a sound basis for further reading of the specialist literature, and an up-to-date appreciation of practical applications and likely trends.

The level, scope and approach of the Series should also appeal to practising engineers and scientists encountering an area of electronics for the first time, or needing a rapid and authoritative update.

Paul A. Lynn 


\section{Preface}

The ability for computers to communicate with each other has advanced very rapidly in the past decade. It has been a principal driving force behind the information technology revolution. It is now standard practice for an organisation to link all its computing resources into a network, or series of interconnected networks, in order to provide advantages such as access to centralised resources, electronic mail and many others.

There are many books on the market which are called something like data communications, but they are mostly aimed at computer scientists. They tend to gloss over the methods and inherent problems in the physical transport of data, and concentrate on the programming aspects of computers communicating with one another. Conversely there are even more books which are called something like digital communications which are aimed at electronic engineers. These usually include a vast amount of mathematically complex theory, providing a good basis for understanding how any digital link could be set up, but tend to skim over the realities of connecting computers together.

The principal aim of this book is to attempt to bridge that gap; to set a study of the engineering mechanisms for data transfer in the context of data communications, as the term is used by computer scientists. This has, of necessity, involved a number of compromises. A great deal of the mathematical aspects of communications theory has had to be omitted, but this may be no bad thing as the principles can be appreciated without having to wade through acres of integrals! On the other hand, the details of programming for data communications have also been omitted. Throughout, the emphasis is on a systems approach, attempting to provide a guide to the subject, which could then be taken further in the direction of engineering or of computer science, if required.

The book could be used to support an introductory course in digital communications at the second or third year level of an engineering degree course. It could also be used as a support text for computer science courses in data communications. In addition, it could be used by practising engineers, familiar with communications but wishing to update their knowledge in an expanding area. 
The information presented in the book is based on a series of lectures developed for the third year of the Electronic Engineering degree course at the University of Reading. The original sources are a wide variety of books from both ends of the data communications spectrum, the more up-to-date of which are listed in the bibliography.

I would like to thank the series editor, Paul Lynn, for his early encouragement and his constructive comments during the preparation of the manuscript, and Malcolm Stewart, of Macmillan Education, for all his assistance. I would also like to thank Professor D.G. Smith, from the University of Strathclyde, for his detailed and helpful review of the first draft of this book. Of course, I must offer the most sincere thanks to my family, Elaine, Richard and David, for all their help and encouragement. 